\title{
Predicting Australian adults' sun-safe behaviour: Examining the role of personal and social norms
}

Katherine M. White ${ }^{1 *}$, Louise C. Starfelt ${ }^{1}$, Ross McD. Young ${ }^{2}$, Anna L. Hawkes ${ }^{3,4}$, Stuart Leske ${ }^{1}$, and Kyra Hamilton ${ }^{5}$

${ }^{1}$ School of Psychology and Counselling, Queensland University of Technology, Brisbane, Australia.

${ }^{2}$ Faculty of Health, Queensland University of Technology, Brisbane, Australia.

${ }^{3}$ School of Public Health and Social Wok, Queensland University of Technology, Brisbane, Australia.

${ }^{4}$ School of Public Health, Tropical Medicine, and Rehabilitation Sciences, James Cook University, Townsville, Australia.

${ }^{5}$ School of Applied Psychology, Griffith University, Brisbane, Australia.

*Requests for reprints should be addressed to Katherine White, School of Psychology and Counselling, Queensland University of Technology, Victoria Park Road, Kelvin Grove, Queensland, 4059, Australia (e-mail: km.white@qut.edu.au).

Acknowledgements: This study was funded by the Australian Research Council and the Cancer Council Queensland. 


\section{Abstract}

Objectives: To address a scarcity of comprehensive, theory-based research in the Australian context, this study, using a theory of planned behaviour (TPB) framework, investigated the role of personal and social norms to identify the key predictors of adult Australians' sun-safe intentions and behaviour.

Design: The study used a prospective design with two waves of data collection, one week apart.

Methods: Participants were 816 adults (48.2\% men) aged between 18 and 88 years recruited from urban, regional, and rural areas of Australia. At baseline, participants completed a questionnaire assessing the standard TPB predictors (attitude, subjective norm, and perceived behavioural control), past behaviour, behavioural intention, and additional measures of group norms for the referent groups of friends and family, image norm, personal norm, personal choice/responsibility, and Australian identity. Seventy-one percent of the participants ( $\mathrm{n}=$ 577) reported on their sun-safe behaviour in the subsequent week.

Results: Via path modelling, past behaviour, attitude, group norm (friends), personal norm, and personal choice/responsibility emerged as independent predictors of intentions which, in turn, predicted sun-safe behaviour prospectively. Past behaviour, but not perceived behavioural control, had direct effects on sun-safe behaviour. The model explained $61.6 \%$ and $43.9 \%$ of the variance in intention and behaviour, respectively.

Conclusions: This study provides support for the use of a comprehensive theoretical decision-making model to explain Australian adults' sun-safe intentions and behaviours and identifies viable targets for health-promoting messages in this high-risk context. 
Predicting Australian Adults' Sun-Safe Behaviour: Examining the role of personal and social norms

In Australia, melanoma of the skin is the third most common type of cancer (Australian Institute of Health and Welfare, 2012). International comparisons show that, in 2008, the incidence rate of melanoma was 13 times higher than the average world incident rate (Australian Institute of Health and Welfare \& Australasian Association of Cancer Registries, 2010). Consistent with these alarming trends, the northeast state of Queensland in Australia has the highest mortality rate of malignant melanoma in the world (Cancer Council Queensland, 2009). The main cause of both melanoma and non-melanoma cancers is excessive exposure to ultraviolet (UV) sunlight radiation (National Cancer Institute, 2002). Sunlight exposure is a modifiable risk factor and skin cancers are, therefore, largely preventable by engaging in sun-protective behaviours, such as using broad spectrum, waterresistant sun protection factor (SPF) 30+ sunscreen, wearing sun-protective clothing (i.e., hat, long-sleeved shirt and sunglasses), and seeking shade when UV radiation is most intense (usually between 10 am and 3 pm) (Cancer Council Australia, 2012).

While demonstrating great awareness of skin cancer risks, Australians are generally reluctant to follow recommendations relating to sun-safe behaviour (Stanton, Janda, Baade, \& Anderson, 2004; Volkov, Dobbinson, Wakefield, \& Slevin, 2013). International research has identified a number of psychosocial influences on sun-protective behaviour, such as attitudes (Maddock, Redding, Rossi, \& Weinstock, 2005), self-efficacy (Craciun, Schüz, Lippke, \& Schwarzer, 2012), and the perceived attractiveness of a tan (Bränström et al., 2010). In Australia, comprehensive studies have been undertaken to describe sun protection attitudes and practices and how these attitudes and behaviours have changed over time in response to population-based campaigning (e.g., "SunSmart” program; Makin, Warne, Dobbinson, Wakefield, \& Hill, 2013; Volkov et al., 2013). While well-validated theoretical models have 
been investigated in international research to understand people's motivations for and decisions to sun protect (e.g., Bränström, Ullén, \& Brandberg, 2004; Craciun et al., 2012; Turrisi, Hillhouse, Gebert, \& Grimes, 1999), the theory-based literature in Australia is relatively scarce and has focused on young adults or adolescents (e.g., Steen, Peay, \& Owen, 1998; White et al., 2008). Therefore, our theoretical understanding of the decision-making process underlying sun protection practices among adults in this high risk area is limited.

\section{The Theory of Planned Behaviour (TPB)}

As a common decision-making model, the theory of planned behaviour (TPB; Ajzen, 1991) posits that intention is the most proximal determinant of behaviour with intention, in turn, being influenced by attitudes (positive or negative evaluations of performing a behaviour), subjective norm (perceived social pressure to perform or not perform a behaviour), and perceived behavioural control (PBC; perceived ease or difficulty of performing a behaviour; also thought to be a direct predictor of behaviour; Ajzen, 1991). The TPB is a well-established model in meta-analyses (e.g., Armitage \& Conner, 2001; McEachan, Conner, Taylor, \& Lawton, 2011) and in the context of sun protection, sun tanning, and sunbathing (Bränström et al., 2004; Hillhouse, Adler, Drinnon, \& Turrisi, 1997; Jackson \& Aiken, 2000; Jones, Abraham, Harris, Schulz, \& Chrispin, 2001; Myers \& Horswill, 2006; Steen et al., 1998; White et al., 2008). However, there is growing criticism of the utility of the TPB in health psychology applications (e.g., Schwarzer, in press; Sniehotta, Presseau, \& Araujo-Soares, in press) with suggestions that the model is only partially complete in its representation of belief initiation through to behavioural enactment and, thus, unable to explain all of the processes of people's decision-making adequately. Testing theoretical models that provide a more comprehensive explanation of people's healthbehaviour decisions to determine which processes interventions might be most useful to target is vital. It is important, then, to identify the optimal set of predictive pathways that 
allow for the best, yet parsimonious, explanation of behaviour (Hagger, 2009). In the spirit of co-creation involving potential users in the development of behaviour change outcomes (Abraham et al., 2012), it was considered beneficial to draw from initial qualitative data to inform our understanding of the plausible influences on people's sun-safe decisions, as well as continue to examine the utility of integrating alternative sources of norms, based on established theories such as social identity theory (Tajfel \& Turner, 1986) and selfcategorisation theory (Turner, Hogg, Oakes, Reicher, \& Wetherell, 1987), into the TPB.

\section{Criticisms of the TPB}

Despite support for the model, a major criticism of the TPB relates to its weak normative component (e.g., Conner \& Armitage, 1998; Rivis \& Sheeran, 2003). The varying importance of normative influences for different individuals and across different behaviours likely accounts, to some extent, for the limited predictive utility of the subjective norm component; however, meta-analytic data strongly indicate measurement and conceptualisation issues (Armitage \& Conner, 2001). Accordingly, some researchers have suggested augmenting the TPB by incorporating refined, theory-based measures of normative influences (e.g., White, Hogg, \& Terry, 2002). These influences have included group norms, which represent perceived normative support of specific salient referent groups (Terry \& Hogg, 1996), and societal media image norms, which are cognitive representations of stereotypical members of particular groups (e.g., tanned people) (Jackson \& Aiken, 2000). For some behaviours, an individual's personal values about whether one "should" perform a behaviour may be particularly important also (Schwartz, 1977).

Group norm. Group norm stems from social identity (Tajfel \& Turner, 1986) and selfcategorisation (Turner et al., 1987) perspectives which posit that people's behaviours are influenced by the perceived expectations and actions of members of specific, salient, reference groups. There is accumulating support for the role of group norms that 
simultaneously challenges the central theoretical role of subjective norm in the prediction of intentions in the overall TPB literature (e.g., Fielding, Terry, Masser, \& Hogg, 2008; Johnston \& White, 2003; White, Terry, \& Hogg, 1994), and in the sun safety domain (e.g., Jackson \& Aiken, 2000; Terry \& Hogg, 1996).

Image norm. Another important normative influence of sun-safe behaviour relates to societal image ideals that are reflected in the media. For example, people who perceive that a tan looks healthy and attractive (Dixon, Warne, Scully, Wakefield, \& Dobbinson, 2011; Sahn, McIlwain, Magee, Veledar, \& Chen, 2012) may expose themselves intentionally to the sun to develop a tan despite being aware of skin cancer risks. In relation to sun safety, image norms (Jackson \& Aiken, 2000) are cognitive representations of tanned and pale people (stereotypes) and are tied to individuals' self-presentational concerns about their image. These norms are broader and more distant from the individual compared to the other normative components (i.e., subjective norm, group norm).

The portrayal of tanned models in Australian media is common and consistent with the prevalence of favourable attitudes towards tanning, especially among young women (Dixon et al., 2011). Perceived image norms and the physical desirability of a tan are linked to both intentional tanning (i.e., sunbathing) and poor sun protection (e.g., Cafri et al., 2006; Cokkinides et al., 2001; Kasparian, McLoone, \& Meiser, 2009; Purdue, 2002). Further, programs that focus on changing the normative perceptions about the attractiveness of untanned images have shown promise in producing positive shifts in sun-protective intentions and behaviour (Jackson \& Aiken, 2006).

Personal norm. In addition to other social influences, researchers have also argued for the inclusion of a personal norm in the TPB (e.g., Parker, Manstead, \& Stradling, 1995). Personal norm reflects internalised rules or values that may have moral overtones (Conner \& Armitage, 1998) and engaging (or not engaging) in the target behaviour will, thus, result in 
self-approval or disapproval. Personal norms predict additional variance in intention over and above the standard TPB predictors (Conner \& Armitage, 1998; Rivis, Sheeran, \& Armitage, 2009). Given that sun protection is preventative in nature and failing to perform the behaviour is associated with highly adverse consequences for the individual, an obligation to self may be influential in sun-safe decisions. Furthermore, the high awareness of and knowledge about sun protection and skin cancer risks in the Australian population (Stanton et al., 2004) raised through years of public campaigns (Cancer Council Australia \& The Australiasian College of Dermatologists, 2009; Montague, Borland, \& Sinclair, 2001) may imply highly crystallised personal norms regarding the extent to which one should be performing this health-enhancing behaviour.

\section{The Current Study}

Addressing the paucity of theory-based research in this high-risk context, this study aimed to examine the utility of the TPB integrating group norms, image norm, and personal norm. Given the identified limitations with the TPB (Hagger, 2009; Sniehotta et al., in press), to identify any potential additional influences, it was considered important to draw from a recent qualitative study (Leske, Young, White, \& Hawkes, in press) that explored Australian adults' beliefs about sun-protection. The normative influences of family and friends were prominent in the data, suggesting that these referents are particularly important for sun-safe decisions. In addition to themes explored within the TPB framework, two additional influences were identified. First, the importance of personal choice/responsibility in the decision to sun protect emerged as a theme in participants' responses. Second, participants emphasised the belief that being in the sun and having a tan were part of Australian identity and culture. Therefore, measures assessing these additional influences were included in this study. 
This research builds on White et al.'s (2008) study which examined young people's sunsafe decisions using an extended TPB incorporating group and image norms. The current study also (1) incorporates the influence of personal norm, group norm for the referent group of family and two additional constructs of personal responsibility and national identity based on the prior qualitative findings (Leske et al., in press) and (2) samples participants across a wider age range to assess whether there are important shared determinants among Australian adults. Consistent with the TPB, it was predicted that more positive attitudes (attitude), higher perceived social pressure to perform sun-safe behaviours (subjective norm), and stronger perceptions of control (PBC) would strengthen sun-protective intentions. Through integrating personal and social influences with the TPB, it was expected that increased past behaviour, higher perceived normative support of the specific target groups of friends and family (group norm friends/family), higher endorsement of media image norms for tanness (image norm), and increased obligation to self (personal norm) would strengthen sun-protective intentions. Based on the findings of relevant qualitative research (Leske et al., in press), it was hypothesised that higher agreement that sun-protective behaviour is the expression of personal choice/responsibility and stronger endorsement of the belief that tanness is part of the Australian identity would strengthen sun-protective intentions. Finally, it was expected that more frequent past behaviour and stronger intentions and perceptions of control (PBC) would predict a greater performance of sun-safe behaviours at follow-up, one week later.

\section{Method}

\section{Design and Procedure}

Ethical clearance was obtained from the University's Human Research Ethics Committee. This study used a prospective design with two waves of data collection to predict sun-safe intention and behaviour in a general population sample of Australian adults. An important aim of the data collection was to attain a diverse sample with representation of 
participants from urban, regional, and rural areas, while accounting for attrition between data collection waves. Because the main concern was the diversity of the sample rather than statistical power, we were broadly guided by general recommendation regarding what is considered a "good" sample size for structural equation models (e.g., > 200; Weston \& Gore, 2006) rather than a priori power calculations. Data were collected over a three-month period between March and May 2011 (i.e., Australian Autumn with an average daily sunshine duration ranging between 3-10 hours and an average UV index ranging between 4-11 with averages depending on the geographical area; Australian Bureau of Meteorology, 2012). At Time 1, participants completed a questionnaire assessing the standard TPB predictors (attitude, subjective norm, PBC, intention), past behaviour, and additional influences (group norm for friends and family, image norm, personal norm, personal choice/responsibility, Australian identity). One week later, the Time 2 follow-up questionnaire assessed participants' sun-safe behaviour over the previous week. Time 1 and Time 2 questionnaires were matched via a code identifier. Participants who completed both questionnaires were offered a AUD\$20 shopping voucher.

\section{Participants}

Participants were recruited from major cities $(n=638,78.2 \%)$, inner regional $(n=133$, $16.3 \%)$, outer regional $(n=41,5 \%)$ and remote $(n=4,0.5 \%)$ areas of Australia through snowball sampling, media releases, sporting clubs, and places of employment. Participants completing the baseline questionnaire at Time 1 were men $(n=393,48.2 \%)$ and women $(n=$ $423,51.8 \%)$ aged between 18 and 88 years $(M=39.7$ years, $S D=15.94$ years $)$. The majority of participants held current employment (69.5\%) with the remaining participants reporting that they were unemployed (4.3\%), students (20.7\%) or retired (12.1\%). Most participants had white $(51.8 \%)$ or light brown skin $(20.3 \%)$ before tanning. After perceived excessive sun exposure, the majority of the participants reported sunburnt/sun-damaged skin $(55.6 \%)$. 
At Time 2, 71\% $(n=579)$ of participants reported their sun-safe behaviour performed over the past week. During this time, participants had spent on average 2.2 hours $(S D=2.23$ hours) in the sun on a typical weekday and 3.92 hours $(S D=3.34$ hours $)$ in the sun over the weekend (Saturday and Sunday). There were no significant differences on the demographic or TPB predictor measures between those who did and did not complete the follow-up.

\section{Measures}

The target behaviour of 'sun-safe behaviours' was defined as: using SPF30+, wearing protective clothing (hat, long-sleeved shirt, sunglasses), or seeking shade during the peak hours of the day (between 10am and 3pm) (Cancer Council Australia, 2012). Items were framed with the same level of specificity in terms of the target, action, time, and context (e.g., "Performing sun-safe behaviours every time you go out in the sun for more than 10 minutes during the next week?"; Fishbein \& Ajzen, 1975). All items were scored using a 7-point Likert scale, except for attitude that was scored using a 7-point semantic-differential format. Some reversed items were included and subsequently recoded so that scale items were in the same (positive) direction. Items were averaged to create scale scores for cases with (at least) two thirds of the scale items completed.

Questionnaire. Six items assessed attitude toward performing sun-safe behaviours: "Performing sun-safe behaviours every time I go out in the sun for more than 10 minutes during the next week would be: 1 pleasant to 7 unpleasant; 1 good to 7 bad; 1 wise to 7 unwise; 1 difficult to 7 easy; 1 nice to 7 awful; 1 negative to 7 positive”. Three items assessed subjective norm: "Those people who are important to me would want me to perform sun-safe behaviours"; "Most people who are important to me would approve of me performing sunsafe behaviours" and; "Most people who are important to me would think that I should perform sun-safe behaviours", 1 strongly disagree to 7 strongly agree. Four items assessed perceived behavioural control (PBC): "I have complete control over whether I perform sun- 
safe behaviours"; "It is mostly up to me whether I perform sun-safe behaviours"; "If I wanted to it would be easy for me to perform sun-safe behaviours" and; "I am confident that I could perform sun-safe behaviours", 1 strongly disagree to 7 strongly agree. Group norms assessed the perceived normative influence of the two target referent groups of friends and family based on findings of the prior qualitative study (Leske et al., in press). Four items assessed the perceived norm for the referent group friends: "Most of my friends perform sun-safe behaviours"; "My friends think that performing sun-safe behaviours is a good thing to do", 1 strongly disagree to 7 strongly disagree; "How many of your friends members would think that performing sun-safe behaviours every time you are out in the in the sun for more than 10 minutes in the next week is a good thing to do" and; "How many of your friends would perform sun-safe behaviours every time they are out in the sun for more than 10 minutes during the next week?", 1 none to 7 all. The same four questions were then repeated for the referent group family members. The items assessing the perceived norm for friends and family formed the constructs of group norm friends and group norm family. Participants' perceived image norm was assessed by five items based on Jackson and Aiken (2000): "Celebrities and movie stars always seem to have a tan"; "I see more examples of models who do not have a tan on TV and in magazines than I used to"; "I think that to be a successful movie star or TV star you should have a tan"; "It seems that society wants people to have a tan" and; "I can think of many movie stars and TV stars who do not have a tan", 1 strongly disagree to 7 strongly agree. Two items assessed personal norm: "I think I should perform sun-safe behaviours" and; "Performing sun-safe behaviours is something I should do", 1 strongly disagree to 7 strongly agree. Measures for the additional influences of personal choice/responsibility and Australian identity were developed specifically for this study. Personal choice/responsibility was assessed by the items: "I think it is my responsibility to perform sun-safe behaviours every time I am out in the sun for more than 10 minutes" and; 
"It is my personal choice to perform sun-safe behaviours every time I am out in the sun for more than 10 minutes", 1 strongly disagree to 7 strongly agree. Australian identity was assessed by the item: "A person with a tan looks Australian", 1 strongly disagree to 7 strongly agree.

Three items assessed participants' intention to engage in sun safe behaviours in the following week: "I intend to perform sun-safe behaviours"; "I plan to perform sun-safe behaviours" and; "It is likely that I will perform sun-safe behaviours", 1 strongly disagree to 7 strongly agree. One item assessed past behaviour: "Think about the past week. In general, how often did you perform sun-safe behaviours?", 1 never to 7 always. At the Time 2 follow-up, sun-safe behaviour performed in the previous week was assessed with the item "In general, how often did you perform sun-safe behaviours?", 1 never, 7 always.

\section{Statistical Procedure}

Theoretical models specifying the hypothesised relationship between the study's variables were investigated using path modelling generated by AMOS 19. The models were tested using the maximum likelihood estimation method. The $\chi^{2}$ test provided a statistical test of model fit. However, given that even trivial deviations from a perfect model are likely to produce a significant $\chi^{2}$ statistic with large sample sizes (Iacobucci, 2010), the "normed" $\chi^{2}$ statistic $\left(\chi^{2} / \mathrm{df}\right)$ was also examined. Values below 3.00 were considered to indicate acceptable model fit (Kline, 2005). A number of absolute and incremental fit indices were also examined to evaluate model fit and cut-off values were based on $\mathrm{Hu}$ and Bentler's (1999) recommendations (Comparative Fit Index $[\mathrm{CFI}]>$.95; Root Mean-Square Error of Approximation [RMSEA] < .06; Standardised Root Mean-square Residual [SRMR] <.08). Additional paths were incorporated if modification indices indicated significant improvements, provided that these paths were theoretically justified.

\section{Results}


Means, standard deviations, bivariate correlations, and Cronbach's alpha coefficients are shown in Table 1. Most predictor and criterion variables were positively and significantly correlated. However, image norm was unrelated to, and Australian identity was negatively correlated or unrelated to, most of the predictor variables and both were unrelated to sun-safe intention and behaviour. The remaining predictor variables were correlated more strongly to intention than behaviour, consistent with the TPB which conceptualises intention as the most proximal determinant of behaviour. Past behaviour was the strongest correlate of both intention and target behaviour.

[Insert Table 1 about here]

A logistic regression was performed to test whether Time 2 completion was dependent on either of the TPB constructs or personal and social influences measured at Time 1. The Time 1 variables did not predict Time 2 completion, $\chi^{2}(11)=14.26, p=.22$, although, at a bivariate level, group norm family was a significant predictor $(\mathrm{OR}=1.42, p=.003)$. Participants who perceived stronger sun protection norms for family members were more likely to complete the follow-up questionnaire.

Because path modelling requires data with no missing entries (Brown, 2006), cases with missing values $(n=2)$ were removed from the dataset resulting in a final sample of $N=577$. For the initial theoretical model, the standard TPB predictors were allowed to predict intention and $\mathrm{PBC}$ and intention was allowed to predict behaviour. Also, past behaviour was allowed to predict the standard TPB constructs (including intention and behaviour) and the TPB predictor variables and normative influences were allowed to co-vary. Additional influences (group norm friends, group norms family, image norm, personal norm, personal choice/responsibility, and Australian identity) were allowed to predict intention.

The initial model was not a good fit to the data, $\chi^{2}(37)=707.58, p<.001$, normed $\chi^{2}=$ 19.12, $\mathrm{CFI}=.771, \mathrm{RMSEA}=.177, \mathrm{SRMR}=.235$. Modification indices suggested 
improvements to the model with paths added between (1) past behaviour and the additional influences (except for image norm) and between (2) attitude and (a) group norm friends and family and (b) personal norm; (3) PBC and (a) group norm friends and family and (b) personal norm; (4) personal choice/responsibility and (a) attitude, (b) subjective norm, (c) PBC, (d) group norm friends and family, and (e) personal norm; and (5) image norm and Australian identity.

The final model was a good fit to the data, $\chi^{2}(19)=35.69, p=.01$, normed $\chi^{2}=1.88$, CFI $=.994, \mathrm{RMSEA}=.039, \mathrm{SRMR}=.020$. Inspection of the standardised residual covariances supported good model fit given that no values exceeded 2.00, indicating that no important misspecification issues were evident in the data (Anderson \& Gerbing, 1988). The final model indicated that intention and past behaviour had direct effects on sun-safe behaviour. In addition, past behaviour, attitude, group norm friends, personal norm, and personal choice/responsibility significantly influenced intentions. The model explained $61.6 \%$ and $43.9 \%$ of the variance in intention and target behaviour, respectively (see Figure 1).

\section{[Insert Figure 1 about here]}

Given that the influence of personal and social norms on sun-protective intentions may vary depending on people's age, the final model was re-run separately for younger adults (18 to 39 years; $n=321)$ and older adults $(\geq 40$ years; $n=255)$. Path coefficients revealed the same overall pattern of results for the normative influences on sun-protective intentions for younger and older adults.

\section{Discussion}

Extending the work by White et al. (2008), this study examined the utility of the TPB integrating past behaviour, group norm for both friends and family, image norm, personal norm, personal choice/responsibility, and Australian identity to explain Australian adults' sun-safe intentions and behaviour. Consistent with hypotheses, attitude, group norm friends, 
personal norm, and personal choice/responsibility emerged as significant predictors of people's intentions which, in turn, significantly predicted sun-safe behaviour in the subsequent week. With the exception of image norm, past behaviour predicted all standard TPB constructs as well as the additional influences. Contrary to expectations, subjective norm, PBC, group norm family, image norm, and Australian identity did not predict people's sun-safe intentions and PBC did not predict behaviour.

Overall, this study suggests that people who have favourable attitudes towards performing sun-safe behaviour, perceive normative support from friends, feel an obligation to self to be sun safe, and believe that sun-safe behaviour represents the expression of personal choice/responsibility, intend to sun protect. This intention subsequently increases the likelihood of engaging in sun-protective behaviour. In light of recent criticism of the limited predictive utility of the TPB (Sniehotta et al., in press), by integrating personal and social influences with the standard model, a large proportion of variance in sun-safe intentions $(61.9 \%)$ and behaviour (43.9\%) was explained. The predictive power of the model tested in this study exceeded the predictive power of the standard TPB constructs reported in metaanalyses (Armitage \& Conner, 2001). The finding that the additional influences of group norm friends, personal norm, and personal choice/responsibility, but not the standard TPB predictors of subjective norm and $\mathrm{PBC}$, contributed independently to the prediction of intention suggests that the decision-making underlying sun-safe behaviour is determined by specific personal and normative factors. The lack of support for some of the TPB predictors also provides additional evidence for the identified limitations of the standard TPB (e.g., Sniehotta et al., in press) and supports the use of a decision-making model that integrates other theoretical approaches (Hagger, 2009), such as social identity (Tajfel \& Turner, 1986) and self-categorisation (Turner et al., 1987) perspectives. 
Of the standard TPB predictors, only attitude emerged as a significant predictor of behavioural intentions. Coupled with prior sun-safety literature (Hillhouse et al., 1997; White et al., 2008), there is robust evidence to suggest that positive attitudes about being sun safe foster strong intentions to engage in sun-safe behaviour. Contrary to expectations, however, subjective norm and PBC were not significant predictors of behavioural intentions, in conflict with White et al. (2008) who found that both of these constructs were important determinants of young Australians' sun-safe intentions.

It is possible that the inclusion of additional influences in this study, such as personal norm and personal choice/responsibility, weakened the influence of subjective norm and PBC. When both subjective and personal norms are included in empirical tests of the TPB in behavioural domains with a moral or ethical dimension, the target behaviour is usually accounted for by personal rather than subjective norm (Aertsens, Verbeke, Mondelaers, \& Huylenbroeck, 2009; Kurland, 1995). This observation may, in part, be due to the differential contextual relevance of subjective and personal norms but, also, to the conceptualisation and measurement issues of the former (Armitage \& Conner, 2001). The consequent self-approval of staying protected from the sun may, then, according to current findings, represent a key motivational factor in sun-safe decisions.

Similarly, it is possible that perceptions of personal choice and responsibility are more relevant to individuals' sun-safe intentions than perceptions of control (PBC). For a healthrelated behaviour that is perceived to be under high volitional control (as indicated by the mean for PBC in the present study), an individual's decision to engage in this behaviour may reflect a conscious choice to assume responsibility for one's health rather than the perceived ability to perform the behaviour. The strong emphasis on individual responsibility for health (and harm) in contemporary liberal cultures has been noted in the broader health literature (e.g., Harley et al., 2011; Leichter, 2003; McDonald \& Slavin, 2010) and arguably reflects 
the societal norms of an individualistic culture. In the context of sun protection, increased individual responsibility for sun-safe decisions parallels with an increasing desire for independence in the adolescent years (Young, Logan, Lovato, Moffat, \& Shoveller, 2005). It is possible that, while perceived control may still be important for young people (e.g., White et al., 2008), personal choice and responsibility may be the driver of adults' sun-safe intentions.

This study also suggests that social factors play a significant role in Australian adults' sun-safety decision. Participants who perceived strong normative support among friends to sun protect indicated greater behavioural intentions. This finding highlights the importance of the perceived norm of relevant referent groups (group norm) in guiding individual decisionmaking and provides support for a broader TPB literature which draws on a social identity approach of normative influence (e.g., Johnston \& White, 2003; Terry \& Hogg, 1996; Terry, Hogg, \& White, 1999). Among young adults, the perceived norm of friends to engage in health-protective behaviour represents a key motivating factor (e.g., Hamilton \& White, 2008; White et al., 2008). This study demonstrates that the friendship group remains an important reference of normative influence in adulthood but the perceived norms of family members are not influential. Further, in additional analyses testing the model on a subsample of participants with children/dependent children (aged 18 years and under), family group norm did not emerge as a significant predictor of intentions. Thus, although a preliminary qualitative study identified family considerations as influential in adults' sun-safe decisions (Leske et al., in press), it was the perceived normative support of friends that was important in this context. For future research it may be useful to establish, for those with children, whether the impact of friendship groups comprising other parents' impact on sun-safety decisions as has been demonstrated in TPB studies of parents examining behaviours such as physical activity decisions (Hamilton \& White, 2012). 
The strongest predictor of sun-safe intentions was personal norm, suggesting that the feeling of personal obligation to stay protected from the sun to avoid the adverse healthrelated consequences of sun exposure strengthen people's sun-safe intentions. The powerful influence of internal pressure to sun protect is a possible indicator that cancer agencies' persistent efforts to promote this behaviour in a high-risk context have been successful in fostering strong personal norms. Coupled with the belief that sun protection is the reflection of an individual's choice and personal responsibility, this study's findings demonstrate that Australian adults' sun-safe intentions are guided strongly by personal (internal) factors.

Although prior literature suggests that the perceived attractiveness of a tan is an important determinant of sun-safety related behaviours, such as sunbathing and sunbed use (Bränström et al., 2004; Cafri et al., 2006), neither media image norms nor the perception that a tan is a part of the Australian identity predicted sun-safe intentions in this sample.

Consistent with White et al. (2008) and Jackson and Aiken's (2000) conclusions, this finding may indicate that more immediate influences (e.g., group norm) are stronger than wider societal and cultural norms.

Based on the findings that attitude, group norm friends, personal norm, and personal choice/responsibility are key determinants in sun-safe intentions, future interventions and campaigns should target these factors to increase sun-protective intentions and behaviour among Australian adults, ideally using a multifaceted approach which incorporates these factors in parallel. Ongoing Australian community-based campaigns (e.g., "SunSmart") have aimed to improve awareness and knowledge about UV exposure and messages have to a large extent been presented in the form of narratives of skin cancer survivors or reminders to be sun safe (e.g., "Slip [on sun-protective clothing]! Slop [on SPF 30+ sunscreen]! Slap [on a broad brimmed hat]! Seek [shade]! Slide [on sunglasses]!.”). Population-based surveys have established an improvement in attitudes and behaviour over time which corresponds with the 
public campaigning of these sun-safe messages (Makin et al., 2013; Volkov et al., 2013). More recently, SunSmart campaign messages have focused on negative sun-protective beliefs (e.g., "There's nothing healthy about a tan") (see www.sunsmart.com.au). In addition to challenging these negative beliefs, the results of our study suggest that campaigns should also focus on fostering positive attitudes (e.g., sun protection is wise) and emphasise the approval of specific, contextually salient referent groups (i.e., friendship groups). Further, the present study indicates that messages that aim to strengthen people's notions that sun-safe decisions reflect the expression of personal responsibility and obligation to self may increase the effectiveness of these campaigns.

There were a number of strengths to this study. First, the study used a comprehensive theoretical decision-making model to predict sun-safe intentions and behaviour in a prospective design which addresses the scarcity of theory-based research in the Australian context. Importantly, in an effort to examine a wide range of possible influences on people's sun-safe decisions, the study drew from relevant recent qualitative findings (Leske et al., in press). Second, a large, demographically diverse sample of Australian adults was obtained from urban, regional, and rural locations. Despite these strengths, this study had limitations. The Time 2 completion was not completely random, given that participants with stronger group norms for family members were more likely to complete the follow-up questionnaire. However, given that group norm family was not a significant predictor of intention in our final model, we do not believe that this selective attrition biased the main analysis significantly. A single-item measure of sun-safe behaviour was used which may be less reliable compared to multi-item measures. Also, self-report may have inflated estimates of sun-protective behaviour; however, previous research demonstrates an acceptable overlap between self-report and objective measures of sun exposure as well as sun-protective behaviours (Hillhouse, Turrisi, Jaccard, \& Robinson, 2012; Yaroch, Reynolds, Buller, Maloy, 
\& Geno, 2006). It is acknowledged that validated measures of sun protection are available (Glanz et al., 2008) which recognise the distinct decisional and preparatory processes (e.g., sunscreen use, sun exposure avoidance etc.). The use of a standardised measure of sun protection practices is important to allow for comparisons between populations and is advised for future studies. The sunshine duration and UV index vary substantially between geographical areas of Australia; Given that sun protection is likely to be a seasonal behaviour, differences in weather conditions may have influenced participants' use of sunprotective measures. Furthermore, the time interval between data collection points was short and, accordingly, future research could explore whether the personal and social influences examined in this study can predict sun protection outcomes in the longer term. Finally, it should be noted that subjective norm and personal norm were correlated strongly, indicating a high overlap between the constructs. However, the correlation did not exceed the scale reliability for either variable, suggesting that these norms were conceptually distinct.

Overall, while this study offered some support to the standard TPB predictors (i.e., attitude-intentions, intention-behaviour) as the main drivers of adults sun-safe decisions, other forms of social influence comprising friendship group norm and personal norm (rather than subjective norm) emerged as important, while a sense of personal choice or responsibility appeared to be more relevant in this context than perceptions of control. Future research should examine the validity of these findings, especially those related to a sense of personal choice or responsibility, in other, especially high-risk, areas. Interventions targeting the main constructs identified in this research will allow an assessment of whether manipulating the strong influences identified for adults in the present study encourages compliance with sun-safe guidelines, ultimately reducing the morbidity and mortality burden associated with skin cancer. 


\section{References}

Abraham, C., Britten, N., Dean, S., Greaves, C., Lloyd, J., Poltawski, L., \& Wyatt, K. (2012). Creating change that counts: Evidence-led co-creation as a pathway to impact. The European Health Psychologist: Bulletin of the European Health Psychology Society, 14(3), 64-69. doi: 10.1037/e544782013-004

Aertsens, J., Verbeke, W., Mondelaers, K., \& Huylenbroeck, G. V. (2009). Personal determinants of organic food consumption: A review. British Food Journal, 111(10), 1140-1167. doi: 10.1108/00070700910992961

Ajzen, I. (1991). The theory of planned behavior. Organizational Behavior and Human Decision Processes, 50(2), 179-211. doi: 10.1016/0749-5978(91)90020-t

Anderson, J. C., \& Gerbing, D. W. (1988). Structural equation modeling in practice: A review and recommended two-step approach. Psychological Bulletin, 103(3), 411423. doi: 10.1037/0033-2909.103.3.411

Armitage, C. J., \& Conner, M. (2001). Efficacy of the theory of planned behaviour: A metaanalytic review. British Journal of Social Psychology, 40(4), 471. doi: $10.1348 / 014466601164939$

Australian Bureau of Meteorology. (2012). Maps of average conditions. Retrieved 4 August 2013, from http://www.bom.gov.au/climate/averages/maps.shtml

Australian Institute of Health and Welfare. (2012). Cancer incidence projections Australia, 2011 to 2020. (Cancer series no. 66. Cat. no. CAN 62). Canberra: Author.

Australian Institute of Health and Welfare, \& Australasian Association of Cancer Registries. (2010). Cancer in Australia 2010: An overview. (Cancer series no. 60. Cat no. CAN 56). Canberra: Author.

Bränström, R., Kasparian, N. A., Yu-mei, C., Affleck, P., Tibben, A., Aspinwall, L. G., . . Hocevar, M. (2010). Predictors of sun protection behaviors and severe sunburn in an 
international online study. Cancer Epidemiology, Biomarkers \& Prevention, 19(9), 2199-2210. doi: 10.1158/1055-9965.EPI-10-0196

Bränström, R., Ullén, H., \& Brandberg, Y. (2004). Attitudes, subjective norms and perception of behavioural control as predictors of sun-related behaviour in Swedish adults. Preventive Medicine: An International Journal Devoted to Practice and Theory, 39(5), 992-999. doi: 10.1016/j.ypmed.2004.04.004

Brown, T. A. (2006). Confirmatory factor analysis for applied research. New York, NY: Guilford Press.

Cafri, G., Thompson, J. K., Roehrig, M., van den Berg, P., Jacobsen, P. B., \& Stark, S. (2006). An investigation of appearance motives for tanning: The development and evaluation of the Physical Appearance Reasons For Tanning Scale (PARTS) and its relation to sunbathing and indoor tanning intentions. Body Image, 3(3), 199-209. doi: 10.1016/j.bodyim.2006.05.002

Cancer Council Australia. (2012). Skin cancer. Retrieved December 11, 2012, from http://www.cancer.org.au/about-cancer/types-of-cancer/skin-cancer.html

Cancer Council Australia, \& The Australiasian College of Dermatologists. (2009). Skin cancer prevention: A blue chip investment in health. National Skin Cancer Committee and Cancer Council Australia, Victoria.

Cancer Council Queensland. (2009). Skin cancer. Retrieved February 4, 2013, from http://www.cancerqld.org.au/page/prevention/skin_cancer/

Cokkinides, V. E., Johnston-Davis, K., Weinstock, M., O'Connell, M. C., Kalsbeek, W., Thun, M. J., \& Wingo, P. A. (2001). Sun exposure and sun-protection behaviors and attitudes among U.S. youth, 11 to 18 years of age. Preventive Medicine: An International Journal Devoted to Practice and Theory, 33(3), 141-152. doi: 10.1006/pmed.2001.0877 
Conner, M., \& Armitage, C. J. (1998). Extending the theory of planned behavior: A review and avenues for further research. Journal of Applied Social Psychology, 28(15), 14291464. doi: 10.1111/j.1559-1816.1998.tb01685.x

Craciun, C., Schüz, N., Lippke, S., \& Schwarzer, R. (2012). A mediator model of sunscreen use: A longitudinal analysis of social-cognitive predictors and mediators. International Journal of Behavioral Medicine, 19(1), 65-72. doi: 10.1007/s12529011-9153-x

Dixon, H. G., Warne, C. D., Scully, M. L., Wakefield, M. A., \& Dobbinson, S. J. (2011). Does the portrayal of tanning in Australian women's magazines relate to real women's tanning beliefs and behavior? Health Education \& Behavior, 38(2), 132-142. doi: $10.1177 / 1090198110369057$

Fielding, K. S., Terry, D. J., Masser, B. M., \& Hogg, M. A. (2008). Integrating social identity theory and the theory of planned behaviour to explain decisions to engage in sustainable agricultural practices. British Journal of Social Psychology, 47(1), 23-48. doi: $10.1348 / 014466607 \times 206792$

Fishbein, M., \& Ajzen, I. (1975). Belief, attitude, intention, and behavior: An introduction to theory and research. Reading, MA: Addison-Wesley.

Glanz, K., Yaroch, A. L., Dancel, M., Saraiya, M., Crane, L. A., Buller, D. B., . . Robinson, J. K. (2008). Measures of sun exposure and sun protection practices for behavioral and epidemiologic research. Archives of Dermatology, 144(2), 217-222. doi: 10.1001/archdermatol.2007.46

Hagger, M. S. (2009). Theoretical integration in health psychology: Unifying ideas and complementary explanations. British Journal Of Health Psychology, 14(2), 189-194. doi: $10.1348 / 135910708 \times 397034$ 
Hamilton, K., \& White, K. M. (2008). Extending the theory of planned behavior: The role of self and social influences in predicting adolescent regular moderate-to-vigorous physical activity. Journal of Sport \& Exercise Psychology, 30(1), 56-74.

Hamilton, K., \& White, K. M. (2012). Social influences and the physical activity intentions of parents of young-children families: An extended theory of planned behavior approach. Journal of Family Issues, 33(10), 1351-1372. doi:

\section{$10.1177 / 0192513 X 12437151$}

Harley, K., Willis, K., Gabe, J., Short, S. D., Collyer, F., Natalier, K., \& Calnan, M. (2011). Constructing health consumers: Private health insurance discourses in Australia and the United Kingdom. Health Sociology Review, 20(3), 306-320.

Hillhouse, J. J., Adler, C. M., Drinnon, J., \& Turrisi, R. (1997). Application of Azjen's theory of planned behavior to predict sunbathing, tanning salon use, and sunscreen use intentions and behaviors. Journal of Behavioral Medicine, 20(4), 365-378. doi: 10.1023/A:1025517130513

Hillhouse, J. J., Turrisi, R., Jaccard, J., \& Robinson, J. (2012). Accuracy of self-reported sun exposure and sun protection behavior. Prevention Science, 13(5), 519-531. doi: $10.1007 / \mathrm{s} 11121-012-0278-1$

Hu, L.-t., \& Bentler, P. (1999). Cutoff criteria for fit indexes in covariance structure analysis: Conventional criteria versus new alternatives. Structural Equation Modeling: A Multidisciplinary Journal, 6(1), 1-55. doi: 10.1080/10705519909540118

Iacobucci, D. (2010). Structural equations modeling: Fit Indices, sample size, and advanced topics. Journal of Consumer Psychology, 20(1), 90-98. doi:

10.1016/j.jcps.2009.09.003

Jackson, K. M., \& Aiken, L. S. (2000). A psychosocial model of sun protection and sunbathing in young women: The impact of health beliefs, attitudes, norms, and self- 
efficacy for sun protection. Health Psychology, 19(5), 469-478. doi: 10.1037/02786133.19.5.469

Jackson, K. M., \& Aiken, L. S. (2006). Evaluation of a multicomponent appearance-based sun-protective intervention for young women: Uncovering the mechanisms of program efficacy. Health Psychology, 25(1), 34-46. doi: 10.1037/0278-6133.25.1.34

Johnston, K. L., \& White, K. M. (2003). Binge-drinking: A test of the role of group norms in the theory of planned behaviour. Psychology \& Health, 18(1), 63-77. doi: $10.1080 / 0887044021000037835$

Jones, F., Abraham, C., Harris, P., Schulz, J., \& Chrispin, C. (2001). From knowledge to action regulation: Modeling the cognitive prerequisites of sun screen use in Australian and UK samples. Psychology \& Health, 16(2), 191-206. doi: $10.1080 / 08870440108405499$

Kasparian, N. A., McLoone, J. K., \& Meiser, B. (2009). Skin cancer-related prevention and screening behaviors: A review of the literature. Journal of Behavioral Medicine, 32(5), 406-428. doi: 10.1007/s10865-009-9219-2

Kline, R. B. (2005). Principles and practice of structural equation modeling (2nd ed.). New York, NY US: Guilford Press.

Kurland, N. B. (1995). Ethical intentions and the theories of reasoned action and planned behavior. Journal of Applied Social Psychology, 25(4), 297-313. doi: 10.1111/j.15591816.1995.tb02393.x

Leichter, H. M. (2003). 'Evil habits' and 'personal choices': Assigning responsibility for health in the 20th century. Milbank Quarterly, 81(4), 603-626. doi: 10.1046/j.0887378X.2003.00296.x

Leske, S., Young, R. M., White, K. M., \& Hawkes, A. L. (in press). A qualitative exploration of sun safety beliefs among Australian adults. Australian Psychologist. 
Maddock, J. E., Redding, C. A., Rossi, J. S., \& Weinstock, M. A. (2005). Development and validation of an appearance motivation attitudes scale for sun protection. Psychology \& Health, 20(6), 775-788. doi: 10.1080/14768320500165944

Makin, J. K., Warne, C. D., Dobbinson, S. J., Wakefield, M. A., \& Hill, D. J. (2013). Population and age-group trends in weekend sun protection and sunburn over two decades of the SunSmart programme in Melbourne, Australia. British Journal of Dermatology, 168(1), 154-161. doi: 10.1111/bjd.12082

McDonald, K., \& Slavin, S. (2010). My body, my life, my choice: Practices and meanings of complementary and alternative medicine among a sample of Australian people living with HIV/AIDS and their practitioners. AIDS Care, 22(10), 1229-1235. doi: $10.1080 / 09540121003668094$

McEachan, R. R. C., Conner, M., Taylor, N. J., \& Lawton, R. J. (2011). Prospective prediction of health-related behaviours with the Theory of Planned Behaviour: A meta-analysis. Health Psychology Review, 5(2), 97-144. doi: $10.1080 / 17437199.2010 .521684$

Montague, M., Borland, R., \& Sinclair, C. (2001). Slip! Slop! Slap! and SunSmart, 19802000: Skin cancer control and 20 years of population-based campaigning. Health Education \& Behavior, 28(3), 290-305. doi: 10.1177/109019810102800304

Myers, L. B., \& Horswill, M. S. (2006). Social cognitive predictors of sun protection intention and behavior. Behavioral Medicine, 32(2), 57-63. doi: 10.3200/BMED.32.2.57-63

National Cancer Institute. (2002). What you need to know about skin cancer: Risk factors. Retrieved September 14, 2012, from http://www.cancer.gov/cancertopics/wyntk/skin/ 
Parker, D., Manstead, A. S. R., \& Stradling, S. G. (1995). Extending the theory of planned behaviour: The role of personal norm. British Journal of Social Psychology, 34(2), 127-137. doi: 10.1111/j.2044-8309.1995.tb01053.x

Purdue, M. P. (2002). Predictors of sun protection in Canadian adults. Canadian Journal of Public Health, 93(6), 470-474.

Rivis, A., \& Sheeran, P. (2003). Descriptive norms as an additional predictor in the theory of planned behaviour: A meta-analysis. Current Psychology, 22(3), 218-233. doi: $10.1007 / \mathrm{s} 12144-003-1018-2$

Rivis, A., Sheeran, P., \& Armitage, C. J. (2009). Expanding the affective and normative components of the theory of planned behavior: A meta-analysis of anticipated affect and moral norms. Journal of Applied Social Psychology, 39(12), 2985-3019. doi: $10.1111 /$ j.1559-1816.2009.00558.x

Sahn, R. E., McIlwain, M. J., Magee, K. H., Veledar, E., \& Chen, S. C. (2012). A crosssectional study examining the correlation between sunless tanning product use and tanning beliefs and behaviors. Archives of Dermatology, 148(4), 448-454.

Schwartz, S. H. (1977). Normative influences on altruism. In L. Berkowitz (Ed.), Advances in experimental psychology. New York, NY: Academic Press.

Schwarzer, R. (in press). Life and death of health behaviour theories. Health Psychology Review, $x(\mathrm{x})$, x-x. doi: 10.1080/17437199.2013.810959

Sniehotta, F. F., Presseau, J., \& Araujo-Soares, V. (in press). Time to retire the theory of planned behaviour. Health Psychology Review, x, x-x. doi: $10.1080 / 17437199.2013 .869710$

Stanton, W. R., Janda, M., Baade, P. D., \& Anderson, P. (2004). Primary prevention of skin cancer: A review of sun protection in Australia and internationally. Health Promotion International, 19(3), 369-378. doi: 10.1093/heapro/dah310 
Steen, D. M., Peay, M. Y., \& Owen, N. (1998). Predicting Australian adolescents' intentions to minimize sun exposure. Psychology \& Health, 13(1), 111-119. doi: $10.1080 / 08870449808406135$

Tajfel, H., \& Turner, J. C. (1986). The social identity of intergroup relations. In S. Worchel \& W. G. Austin (Eds.), Psychology of intergroup relations (pp. 7-24). Chicago, IL: Nelson-Hall.

Terry, D. J., \& Hogg, M. A. (1996). Group norms and the attitude-behavior relationship: A role for group identification. Personality and Social Psychology Bulletin, 22(8), 776793. doi: $10.1177 / 0146167296228002$

Terry, D. J., Hogg, M. A., \& White, K. M. (1999). The theory of planned behaviour: Selfidentity, social identity and group norms. British Journal of Social Psychology, 38(3), 225-244. doi: 10.1348/014466699164149

Turner, J. C., Hogg, M. A., Oakes, P. J., Reicher, S. D., \& Wetherell, M. S. (1987). Rediscovering the social group: A self-categorization theory. Oxford: Blackwell.

Turrisi, R., Hillhouse, J., Gerbert, C., \& Grimes, J. (1999). Examination of cognitive variables relevant to sunscreen use. Journal of Behavioral Medicine, 22(5), 493-509. doi: $10.1023 / \mathrm{a}: 1018609524523$

Volkov, A., Dobbinson, S., Wakefield, M., \& Slevin, T. (2013). Seven-year trends in sun protection and sunburn among Australian adolescents and adults. Australian And New Zealand Journal Of Public Health, 37(1), 63-69. doi: 10.1111/1753-6405.12012

Weston, R., \& Gore, P. A. (2006). A brief guide to structural equation modeling. Counseling Psychologist, 34(5), 719-751. doi: 10.1177/0011000006286345

White, K. M., Hogg, M., \& Terry, D. (2002). Improving attitude-behavior correspondence through exposure to normative support from a salient ingroup. Basic and Applied Social Psychology, 24(2), 91-103. doi: 10.1207/S15324834BASP2402_2 
White, K. M., Robinson, N. G., Young, R. M., Anderson, P. J., Hyde, M. K., Greenbank, S., . . Baskerville, D. (2008). Testing an extended theory of planned behaviour to predict young people's sun safety in a high risk area. British Journal Of Health Psychology, 13, 435-448. doi: 10.1348/135910707X210004

White, K. M., Terry, D. J., \& Hogg, M. A. (1994). Safer sex behavior: The role of attitudes, norms, and control factors. Journal of Applied Social Psychology, 24(24), 2164-2192. doi: 10.1111/j.1559-1816.1994.tb02378.x

Yaroch, A. L., Reynolds, K. D., Buller, D. B., Maloy, J. A., \& Geno, C. R. (2006). Validity of a sun safety diary using UV monitors in middle school children. Health Education \& Behavior, 33(3), 340-351. doi: 10.1177/1090198105285329

Young, R. A., Logan, C., Lovato, C. Y., Moffat, B., \& Shoveller, J. A. (2005). Sun protection as a family health project in families with adolescents. Journal of Health Psychology, 10(3), 333-344. doi: 10.1177/1359105305051419 
Table 1

Means, Standard Deviations (SD), Bi-variate Correlations, and Reliability (Cronbach's Alpha) for the Predictor Variables and Target

Behaviour $(N=577)$

\begin{tabular}{|c|c|c|c|c|c|c|c|c|c|c|c|c|c|}
\hline Variable & $M(S D)$ & 1 & 2 & 3 & 4 & 5 & 6 & 7 & 8 & 9 & 10 & 11 & 12 \\
\hline 1. Attitude & $5.35(1.14)$ & $(.87)$ & & & & & & & & & & & \\
\hline 2. Subjective norm & $6.02(.94)$ & $.40 * * *$ & $(.88)$ & & & & & & & & & & \\
\hline 3. $\mathrm{PBC}$ & $6.11(.89)$ & $.30 * * *$ & $.40 * * *$ & $(.84)$ & & & & & & & & & \\
\hline 4. Past behaviour & $4.65(1.71)$ & $.48 * * *$ & $.38 * * *$ & $.30 * * *$ & - & & & & & & & & \\
\hline 5. Group norm friends & $4.79(1.13)$ & $.39 * * *$ & $.57 * * *$ & $.33 * * *$ & $.42 * * *$ & $(.83)$ & & & & & & & \\
\hline 6. Group norm family & $5.36(1.11)$ & $.37 * * *$ & $.69 * * *$ & $.31 * * *$ & $.43 * * *$ & $.64 * * *$ & $(.85)$ & & & & & & \\
\hline 7. Image norm & $4.11(.97)$ & -.06 & -.02 & .00 & -.06 & -.07 & -.01 & $(.66)$ & & & & & \\
\hline 8. Personal norm & $6.23(.94)$ & $.50 * * *$ & $.73 * * *$ & $.41 * * *$ & $.48 * * *$ & $.43 * * *$ & $.49 * * *$ & .00 & $(.88 / .79)^{1}$ & & & & \\
\hline 9. Personal choice/resp. & $6.17(.93)$ & $.33 * * *$ & $.47 * * *$ & $.45 * * *$ & $.43 * * *$ & $.36 * * *$ & $.39 * * *$ & -.03 & $.53 * * *$ & $(.61 / .45)^{1}$ & & & \\
\hline 10. Australian identity & $4.05(1.49)$ & $-.12 * *$ & .00 & -.06 & $-.12 * *$ & -.07 & -.04 & $.26 * * *$ & -.02 & -.06 & - & & \\
\hline 11. Intention & $5.44(1.37)$ & $.56^{* * *}$ & $.54 * * *$ & $.35 * * *$ & $.66^{* * *}$ & $.50 * * *$ & $.51^{* * *}$ & .02 & $.62 * * *$ & $.48 * * *$ & -.03 & $(.96)$ & \\
\hline 12. Behaviour & $4.73(1.68)$ & $.45^{* * *}$ & $.26 * * *$ & $.18^{* * * *}$ & $.63 * * *$ & $.36 * * *$ & $.34 * * *$ & .02 & $.36^{* * *}$ & $.32 * * *$ & -.06 & $.57 * * *$ & - \\
\hline
\end{tabular}

Note. PBC = Perceived behavioural control; resp. $=$ responsibility. ${ }^{*} p<.05, * * p<.01, * * * p<.001$.

${ }^{1}$ Two-item scale (Cronbach's Alpha/Pearson's $r$ ) 


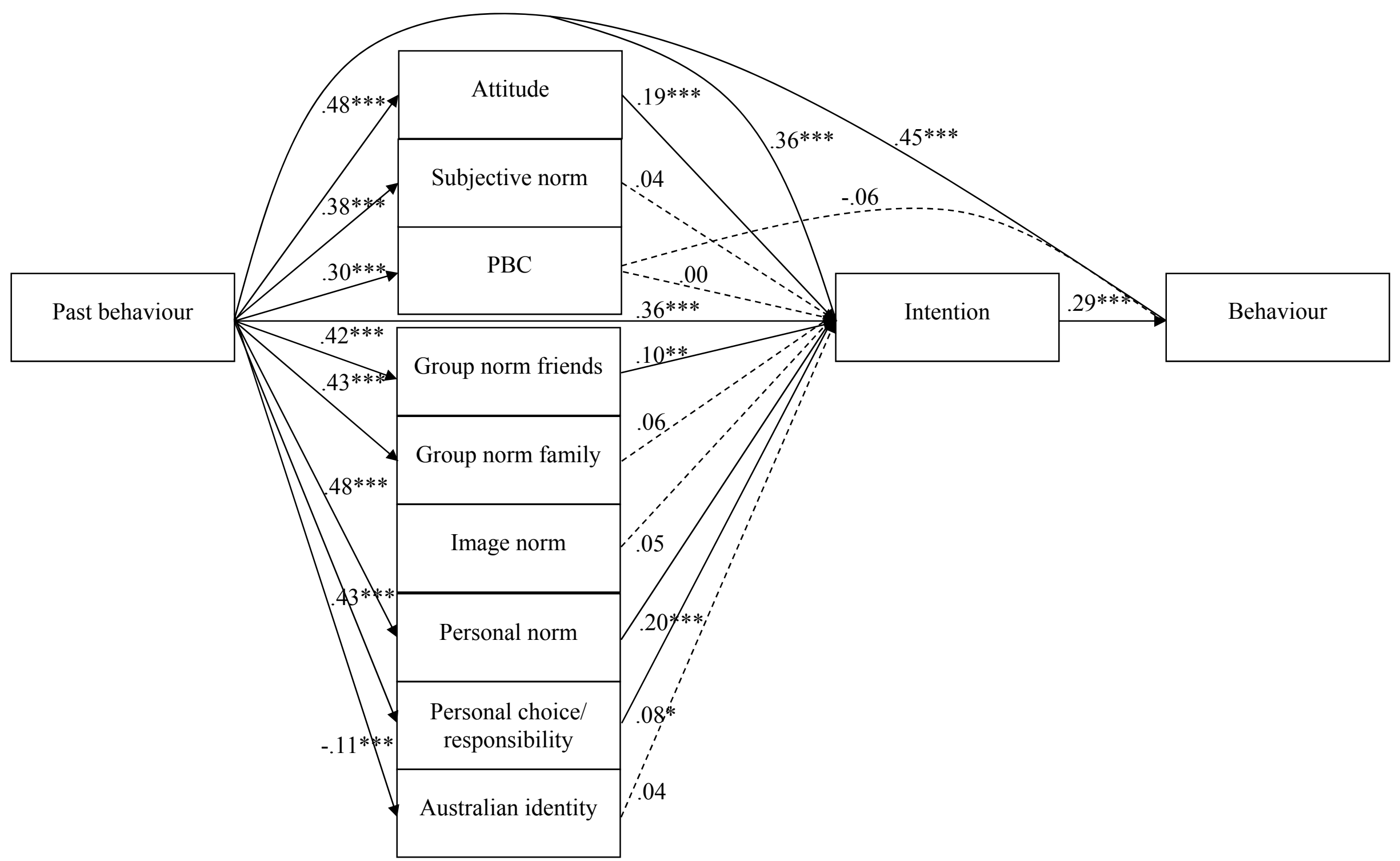


Figure 1. Final model for predicting Australian adults' sun-safe intentions and behaviour $(N=577)$. Note. The figure does not show bidirectional paths. ${ }^{*} p<.05, * * p<.01, * * * p<.001$. 